\title{
Pathophysiological Effect of Oxygen Free Radicals on Mobility and DNA Integrity of Human Seminal Spermatozoa
}

\author{
(Effect of Free Radicals on Human Spermatozoa)
}

\author{
Suada Tinjic \\ Gynecology Polyclinic "Korak do života", \\ Tuzla, Bosnia and Herzegovina
}

\author{
Mirza Ibrisimovic \\ Gynecology Polyclinic "Korak do života", \\ Tuzla, Bosnia and Herzegovina \\ University Sarajevo School of Science and Technology, \\ Sarajevo, Bosnia and Herzegovina
}

\begin{abstract}
Production of free oxygen radicals in greater volume than it is possible for human organism to neutralize, can affect quality of sperm. Reactive oxygen species (ROS) have an effect on mobility of human spermatozoids by changing the structure of membrane and the function of mitochondria, where they are primarily generated. This can affect DNA integrity of spermatozoids and compromise their vitality. Seven male patients, in age between 27 and 44, were examined by standard semen analysis, nitroblue tetrazolium (NBT) assay and sperm vitality test based on eosin and nigrosin staining. From patients with positive NBT test, $40 \%$ of the patients had normal spermiogram results, while $60 \%$ of them had decreased sperm concentration, motility, or both of these parameters below the referent value. In $20 \%$ cases the output of eosin-nigrosin test was below $58 \%$. The NBT test and eoisn-nigrosin test are simple, effective and available tests which can help in better diagnosis of male infertility and should be integrated in routine semen analysis.
\end{abstract}

Keywords- Sperm, Reactive oxygen species, NBT test, Infertility.

\section{INTRODUCTION}

Oxidative stress is a known cause of male infertility, mostly because of its effect on sperm motility and DNA integrity of sperm. Oxidative stress happens when reactive oxygen species are produced more than normal and organism is not able to neutralize them [1]. The oxygen is necessary to maintain physiologic and metabolic balance of sperm cells, but free oxygen radicals can compromise functionality and vitality of sperms [2]. These molecules are very unstable, shortly-lived and very reactive and they "steal" electrons from other structures to reach ground state and in that way they are changing structure of the cell [3]. Spermatozoids are prone to damage by ROS because their membrane contains polyunsaturated fatty acids and cytoplasm does not contain enough antioxidative enzymes. Great production of ROS is located in seminal leukocytes and morphologically abnormal spermatozoids. Clinical implications are different in cases where the ROS sources are seminal leukocytes and in pathological cases where the sperm cells themselves are the source of ROS production. Because of this reason it is important to determine source of ROS in a given sperm sample [4]. It was also shown that the production of ROS is greater in immature sperm cells [5]. Imbalance between levels of ROS and antioxidant capacity of the body can result in abnormalities within the spermatozoa such as defects in sperm head, acrosome or tail [6]. Most of the antioxidant enzymes of the sperm are lost during the process of spermiogenesis and also sperm is present for long period of time in genital tracts of male and women, which makes it more susceptible to the ROS induced damage [7].

\section{METHODS AND MATERIALS}

\section{A. Study design}

All procedures in this study are done in gynecological polyclinic "Korak do života", including examination of seven male patients. After standard semen analysis, NBT test was performed for analysis of ROS presence in spermatozoa and seminal leukocytes. For evaluation of sperm vitality the eosin-nigrosin test was used.

\section{B. NBT Test}

All procedures in this study are done in gynecological polyclinic "'Korak do života", including examination of seven male patients. After standard semen analysis, NBT test was performed for analysis of ROS presence in spermatozoa and seminal leukocytes. For evaluation of sperm vitality the eosinnigrosin test was used.

\section{Eosin-nigrosin test for sperm vitality}

Mix the drop of eosin - nigrosin dye (Semikem) with the drop of semen sample. Make smear and let it dry. Examine under microscope. Uncolored spermatozoa are counted as alive, while spermatozoa in pink or red color are counted as dead. Count percentage of alive spermatozoa that should be in concentration more than $58 \%$.

\section{RESULTS}

A. Determining a source of free radicals by NBT test By damaging of the sperm membrane ROS is affecting mobility of sperms as well as the fusion of egg and spermatozoid. DNA integrity can also be affected by the 
presence of ROS, which causes infertility, poor embryo development and higher rate of miscarriages [4]. Antioxidant therapy can improve semen quality and the medically assisted reproduction outcomes. For this reason it is important to identify ROS in andrology laboratories. Many tests are available to achieve that, and one of the simplest and cheapest is NBT (Nitro Blue Tetrazolium) test. Test is based on the reaction of NBT with cell superoxide which gives rise to formation of formazan that can be detected microscopically or spectrophotometrically. NADPH (nicotinamide adenine dinucleotide phosphate) acts as a protein donor in generation of superoxide anions with the presence of NADPH oxidase from spermatozoids that are turning NBT in formazan. In this way NBT test shows oxidative activity in cell cytoplasm as a source of free radicals production and colors cells dark as indicator of uncontrolled free radical production in examined patients (Figure 1A and 1B).

FIGURE 1. THE NBT TEST (IMAGES WERE TAKEN BY MICROSCOPE). A: POSITIVE RESULT OF NBT TEST WITH 70\% OF ROS IN SPERMATOZOIDS AND 30\% OF ROS IN LEUKOCYTES. B: NEGATIVE RESULTS OF NBT TEST WITH ROS IN SPERMATOZOIDS OF 6\% AND 14\% IN LEUKOCYTES.

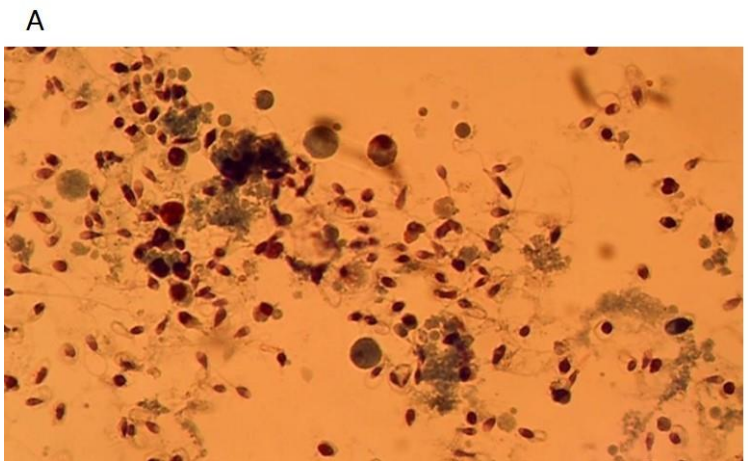

B

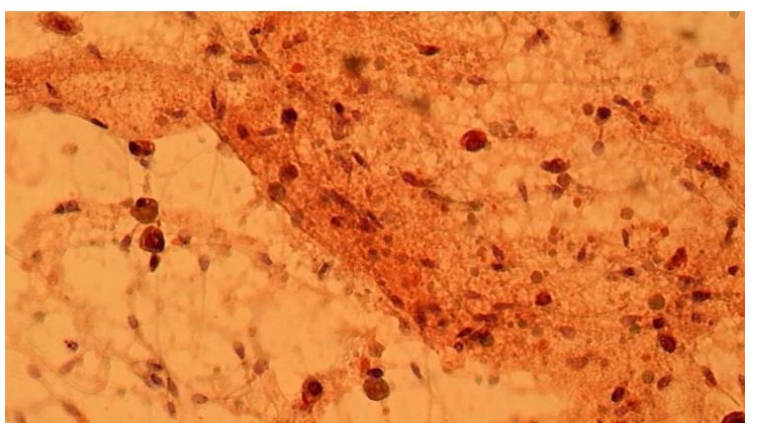

B. Vitality of spermatozoids and eosin-nigrosin test

In standard semen analysis is important to differentiate dead from alive spermatozoa. Alive spermatozoa are recognized by their mobility and appear uncolored in HOS (hypoosmotic swelling) test (Figure 2). However, for differentiating alive, immotile spermatozoa from dead spermatozoa other techniques are needed. They are mostly based on the fact that alive spermatozoa have structurally complete membranes and do not absorb the dye, while dead spermatozoa do, because of disturbed membrane [8]. The eosin-nigrosin test can be used only in diagnostic purposes, while HOS test is used in cases when there is a need to select vital spermatozoa for ICSI (intracytoplasmic sperm injection) procedure [9].

\section{FIGURE 2. THE HOS TEST (IMAGE WAS TAKEN BY MICROSCOPE). RESULTS OF HOS TEST SHOWED THAT 75\% SPERMATOZOA WERE ALIVE.}

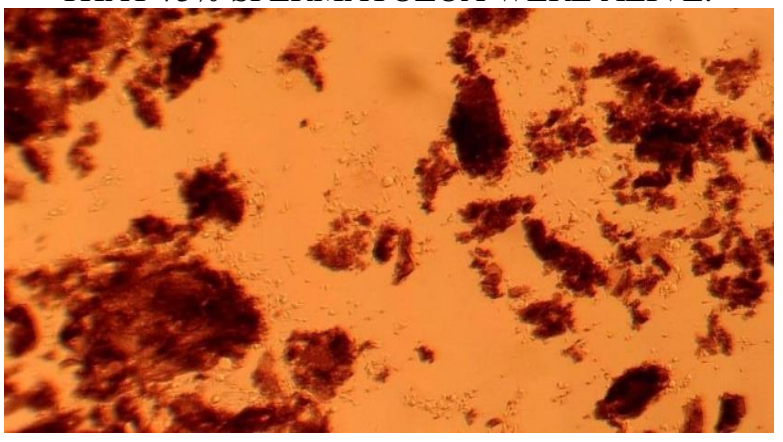

\section{NBT test and patient's diagnosis}

From examined patients in $60 \%$ cases of positive NBT assay, the spermiogram analysis was not normal. Patients had decreased sperm concentration, mobility, or both of these parameters were reduced. In $40 \%$ cases of patients with positive NBT test, they had normal spermiogram results (normozoospermia) (Figure 3). However, 20\% of patients with normal NBT test result had vitality test bellow referent value (Figure 4).

\section{FIGURE 3. POSITIVE NBT TEST. IN 40\% CASES PATIENTS WITH POSITIVE NBT TEST HAD NORMOZOOSPERMIA WITH NORMAL SPERMIOGRAM RESULTS. 20\% OF CASES HAD DECREASED CONCENTRATION OF SPERMATOZOA (OLIGOZOOSPERMIA), 20\% DECREASED SPERM MOBILITY (ASTHENOTOOSPERMIA) AND 20\% BOTH PARAMETERS DECREASED (OLIGOASTHENOZOOSPERMIA).}

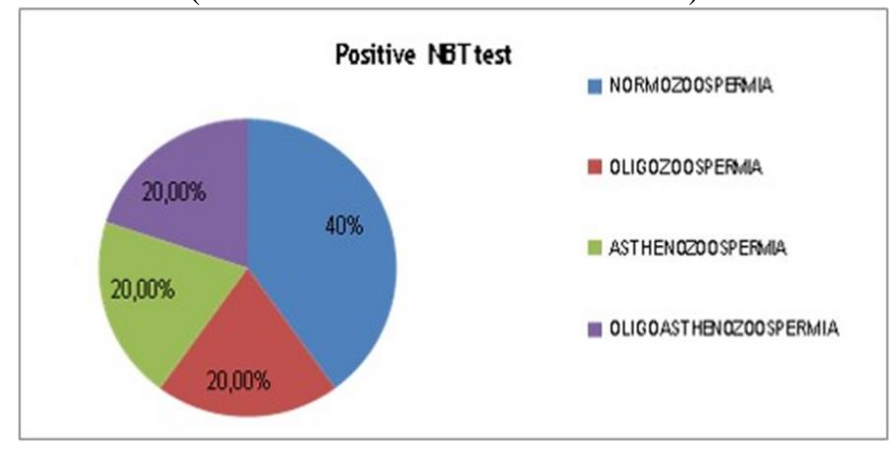




\section{FIGURE 4. SPERM VITALITY TEST. 20\% OF PATIENTS WITH POSITIVE NBT TEST HAD LOW SPERM VITALITY (BELOW 58\%).}

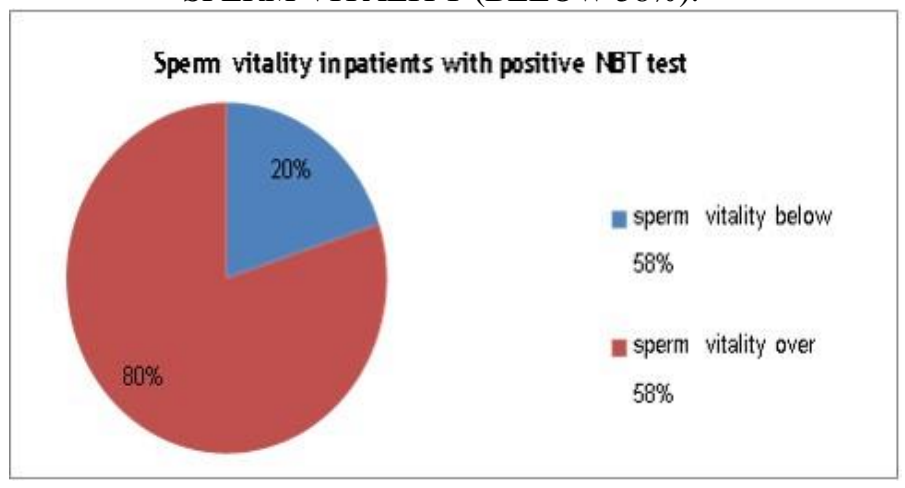

\section{DISCUSSION}

Based on the results of this study it was possible to conclude that the production of ROS in seminal spermatozoa affects their quality. Free radicals influence mobility of spermatozoa by changing the structure of membrane or function of mitochondria [1]. NBT test can be used to investigate production of oxidative stress in seminal leukocytes. In this study sources of oxidative stress were mainly spermatozoa. Oxidative stress in spermatozoa leads to decrease in quality of spermatozoa, their mobility and DNA integrity. In patients with positive NBT test in our study, mobility was decreased, concentration, or both these values. Some patients had normal spermiogram results even with NBT positive test (Figure 3).

Necrospermia is diagnosed in patients who have percentages of dead spermatozoa more than $42 \%$. It is often found in men with microbial infections, spinal cord injury or in case of toxin exposure [10]. The test for sperm vitality used in this study was based on eosin and nigrosine cell staining that works on principle of the permeability of sperm membrane. Vital spermatozoa will not absorb the dye, while dead spermatozoa will appear as colored. This test shows if immotile spermatozoa are dead or if their motility is compromised. In $20 \%$ cases of patients with positive NBT test the sperm vitality was below $58 \%$, which is referent value for this test. We were able to confirm that free radicals can affect DNA integrity of sperm and by that way its vitality as it was indicated in some previous studies $[10,11]$. It was possible to see that disproportional levels of ROS can negatively impair the semen parameters which are associated with male infertility. This can lead to uncontrolled production of ROS and decrease in antioxidant capacity of the seminal plasma [12, 13].

\section{CONCLUSION}

Controlled concentrations of ROS are important for promotion of normal sperm physiological processes, such as acrosome reaction and signaling processes which are necessary for successful fertilization [11]. Only appropriate levels of ROS can prevent pathological damage of spermatozoa. Antioxidative therapy can improve quality of spermatozoa and by that outcome of medically assisted reproduction and natural conception $[1,13]$. There are several antioxidants that enable extenuation of oxidative stress, such as albumin, taurine and some metals (zinc, selenium and manganese) [11, 14-17]. Based on these facts it is very important to analyze the free radicals production, as well as the source of their production. NBT test is easy and commercially available test tool that can be used in routine semen analysis. Beside this vitality test of spermatozoa, such as eosin-nigrosin test, can give clearer picture of male infertility. It can be helpful in defining male infertility and its causes, as well as the outcomes of medically assisted production.

\section{REFERENCES}

[1] Tunc O, Thompson J, Tremellen K. Development of the NBT assay as a marker of sperm oxidative stress. International journal of andrology. 2010 Feb;33(1):13-21

[2] Esfandiari N, Sharma RK, Saleh RA, Thomas Jr AJ, Agarwal A. Utility of the nitroblue tetrazolium reduction test for assessment of reactive oxygen species production by seminal leukocytes and spermatozoa. Journal of Andrology. 2003 Nov 12;24(6):862-70.

[3] Gosalvez J, Tvrda E, Agarwal A. Free radical and superoxide reactivity detection in semen quality assessment: past, present, and future. Journal of assisted reproduction and genetics. 2017 Jun 1;34(6):697-707.

[4] Zorn B, Vidmar G, Meden-Vrtovec H. Seminal reactive oxygen species as predictors of fertilization, embryo quality and pregnancy rates after conventional in vitro fertilization and intracytoplasmic sperm injection. International Journal of Andrology. 2003 Oct;26(5):279-85.

[5] Gil-Guzman E, Ollero M, Lopez MC, Sharma RK, Alvarez JG, Thomas Jr AJ, Agarwal A. Differential production of reactive oxygen species by subsets of human spermatozoa at different stages of maturation. Human Reproduction. 2001 Sep 1;16(9):1922-30.

[6] Kobayashi CI, Suda T. Regulation of reactive oxygen species in stem cells and cancer stem cells. Journal of cellular physiology. 2012 Feb;227(2):421-30.

[7] Sabeti P, Pourmasumi S, Rahiminia T, Akyash F, Talebi AR. Etiologies of sperm oxidative stress. International Journal of Reproductive Biomedicine. 2016 Apr;14(4):231.

[8] Björndahl L, Söderlund I, Johansson S, Mohammadieh M, Pourian MR, Kvist U. Why the WHO recommendations for eosin-nigrosin staining techniques for human sperm vitality assessment must change. Journal of andrology. 2004 Sep 10;25(5):671-8.

[9] Khalili MA, Mir-Rokni F, Kalantar SM. Application of vitality tests on asthenozoospermic semen from infertile men. Iranian Biomedical Journal. 1999 Jul 15;3(3):77-81.

[10] Samplaski MK, Dimitromanolakis A, Lo KC, Grober ED, Mullen B Garbens A, Jarvi KA. The relationship between sperm viability and DNA fragmentation rates. Reproductive Biology and Endocrinology. 2015 Dec;13(1):42.

[11] Agarwal A, Virk G, Ong C, du Plessis SS. Effect of oxidative stress on male reproduction. The world journal of men's health. $2014 \mathrm{Apr}$ $1 ; 32(1): 1-7$.

[12] Trussell JC. Optimal diagnosis and medical treatment of male infertility. InSeminars in reproductive medicine 2013 Jul (Vol. 31, No. 04, pp. 235-236). Thieme Medical Publishers.

[13] Lanzafame FM, La Vignera S, Vicari E, Calogero AE. Oxidative stress and medical antioxidant treatment in male infertility. Reproductive biomedicine online. 2009 Nov 1;19(5):638-59.

[14] Bansal AK, Bilaspuri GS. Impacts of oxidative stress and antioxidants on semen functions. Veterinary medicine international. 2011;2011.

[15] Sharma RK, Agarwal A. Role of reactive oxygen species in male infertility. Urology. 1996 Dec 1;48(6):835-50.

[16] Lombardo F, Sansone A, Romanelli F, Paoli D, Gandini L, Lenzi A The role of antioxidant therapy in the treatment of male infertility: an overview. Asian Journal of andrology. 2011 Sep;13(5):690.

[17] Li L, Yang X. The essential element manganese, oxidative stress, and metabolic diseases: Links and interactions. Oxidative medicine and cellular longevity. 2018;2018. 